\section{D Computed Tomography Visualization of Effective Septal Reduction After Alcohol Septal Ablation for Fatal Hypertrophic Obstructive Cardiomyopathy}

Keitaro Akita, MD; Yutaro Kaneko, MD;

Ryota Sato, MD; Keisuke Iguchi, MD;

Kenichiro Suwa, MD; Yuichiro Maekawa, MD

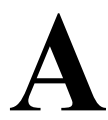

54-year-old woman, diagnosed with hypertrophic obstructive cardiomyopathy (HOCM) complained of exertional dyspnea. After she fell down stairs, a bystander initiated cardiopulmonary resuscitation and subsequently she received an implantable cardioverterdefibrillator (ICD). The AV-delay adjustment improved her left ventricular outflow tract pressure gradient (LVOTPG) from 150 to $65 \mathrm{mmHg}$. However, she still experienced New York Heart Association (NYHA) class III dyspnea. Septal myectomy was recommended but she refused. Instead, she underwent alcohol septal ablation (ASA). Because her maximum septal thickness was $23 \mathrm{~mm}$, an extended "myectomy-like" ablation was necessary. The 4 septal arteries were ablated with $7.5 \mathrm{~mL}$ of ethanol (Figure). Her peak LVOT-PG decreased to $5 \mathrm{mmHg}$. Dyspnea improved to NYHA class I. In the comparison of the 4D computed tomography (4D-CT) before and 6 months after the ablation, her left ventricular mass decreased from 246 to $221 \mathrm{~g}$, while her cardiac output increased from 4.70 to $5.50 \mathrm{~L} / \mathrm{min}$. In this case, the extended "myectomy-like" ablation accomplished adequate septal reduction, ${ }^{1}$ and 4D-CT revealed significant left ventricular volume reduction after ASA, which implied that ASA accomplished an equal extent of septal reduction as a septal myectomy due to septal thinning and consequent reverse remodeling.

\section{Disclosures}

None.

\section{Reference}

1. Maekawa Y, Akita K, Takanashi S. Contemporary septal reduction therapy in drug-refractory hypertrophic obstructive cardiomyopathy. Circ J 2018; 82: 1977-1984.

\section{Supplementary Files}

Supplementary Movie 1. 4D-CT before ASA.

Supplementary Movie 2. 4D-CT at 6 months after ASA.

Please find supplementary file(s);

http://dx.doi.org/10.1253/circj.CJ-21-0922

Received November 8, 2021; accepted November 8, 2021; J-STAGE Advance Publication released online December 2, 2021 Time for primary review: 1 day

Division of Cardiology, Internal Medicine III, Hamamatsu University School of Medicine, Hamamatsu (K.A., Y.K., R.S., K.I., K.S., Y.M.), Japan; Division of Cardiology, Department of Medicine, Columbia University Irving Medical Center, New York, NY (K.A.), USA

Mailing address: Yuichiro Maekawa, MD, PhD, FJCS, Division of Cardiology, Internal Medicine III, Hamamatsu University School of Medicine, 1-20-1 Handayama, Higashi-ku, Hamamatsu 431-3192, Japan. E-mail: ymaekawa@hama-med.ac.jp

All rights are reserved to the Japanese Circulation Society.

For permissions, please e-mail: cj@j-circ.or.jp ISSN-1346-9843

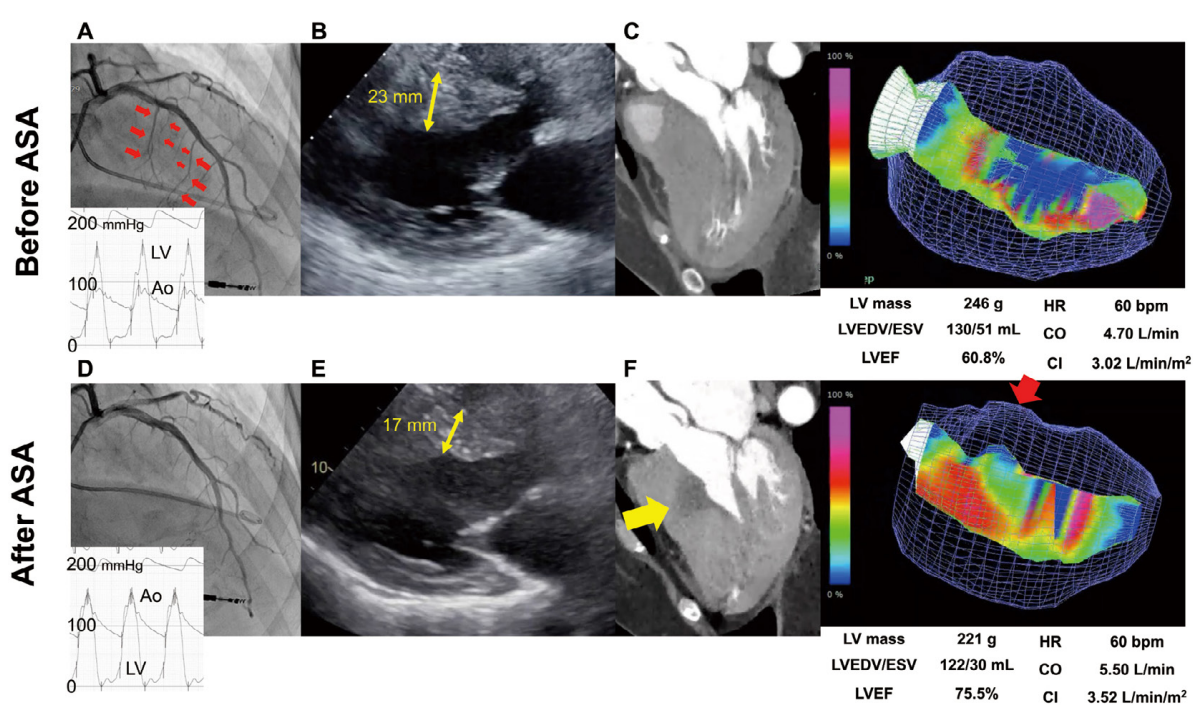

Figure. (A) Angiogram before alcohol septal ablation (ASA). The 4 septal arteries (red arrows) were candidates for ablation. The peak-to-peak pressure gradient was $65 \mathrm{mmHg}$. (B) Echocardiogram before ASA. (C) (Left) Cardiac CT and (Right) CT analysis before ASA. (D) Angiogram after ASA. The pressure gradient was $5 \mathrm{mmHg}$. (E) Echocardiogram at 6 months after ASA. The basal thickness decreased from 23 to $17 \mathrm{~mm}$. (F) (Left) Cardiac CT and (Right) CT analysis at 6 months after ASA. The ablated area became low-density (yellow arrow) and thinner (red arrow). Ao, aorta; Cl, cardiac index; CO, cardiac output; EDV/ESV, end-diastolic/end-systolic volume; EF, ejection fraction; HR, heart rate; LV, left ventricle. 